\title{
EXISTENCE RESULTS, INEQUALITIES AND A PRIORI BOUNDS TO FRACTIONAL BOUNDARY VALUE PROBLEMS
}

\author{
Nicholas Fewster-YounG
}

Abstract. This paper presents new results to fractional boundary value problems in relation to the existence of solutions and providing a priori bounds on all possible solutions subject to a differential inequality. This provides the scope of these results to be applicable to a vast range of problems that may have unrestricted growth to prove the existence of solutions. This contributes to the practically of these results through their application in modelling real world phenomena.

Mathematics subject classification (2020): 26D10, 34A98, 34A34, 34B15, 34C11.

Keywords and phrases: Fractional, boundary value problems, existence results, a priori, fractional inequalities.

\section{REFERENCES}

[1] Ravi P. Agarwal, Maria Meehan and Donal O'Regan, Fixed Point Theory and Applications, Cambridge Tracts in Mathematics, 141, Cambridge University Press, Cambridge, 2001.

[2] Ahmed Alsaedi, Bashir Ahmad and Mokhtar Kirane, Maximum principle for certain generalized time and space fractional diffusion equations, Quart. Appl. Math. 73, 1, 2015, 163-175.

[3] Abdon AtANGAna, Fractional operators with constant and variable order with application to geohydrology, Academic Press, London, 2018.

[4] A. BABAKHANi AND VARShA DAFTARDAR-GEJJi, Existence of positive solutions of nonlinear fractional differential equations, J. Math. Anal. Appl. 278, 2, 2003, 434-442.

[5] ZhANBIng BAI AND HAISHEn LÜ, Positive solutions for boundary value problem of nonlinear fractional differential equation, J. Math. Anal. Appl., 311, 2, 2005, 495-505.

[6] K. Diethelm, N. J. Ford, A. D. Freed AND Yu. LuchKo, Algorithms for the fractional calculus: a selection of numerical methods, Comput. Methods Appl. Mech. Engrg. 194, 6-8, (2005), 743-773.

[7] Kai Diethelm and Neville J. Ford, Analysis of fractional differential equations, J. Math. Anal. Appl. 265, 2, (2002), 229-248.

[8] Kai Diethelm, The analysis of fractional differential equations. An application-oriented exposition using differential operators of Caputo type, Lecture Notes in Mathematics, 2004, Springer-Verlag, Berlin, 2010.

[9] Nicholas Fewster-Young And Christopher C. Tisdell, The existence of solutions to second-order singular boundary value problems, Nonlinear Anal. 75, 13, (2012), 4798-4806.

[10] Martin Bohner and Nicholas Fewster-Young, Discrete Fractional Boundary Value Problems and Inequalities, 24, 6, (2021), 1777-1796, https://doi.org/10.1515/fca-2021-0077.

[11] Nicholas Fewster-Young, Existence results for nonlinear Caputo fractional boundary value problems, Submitted (In Review), 2021.

[12] Philip Hartman, On boundary value problems for systems of ordinary, nonlinear, second order differential equations, Trans. Amer. Math. Soc. 96, (1960), 493-509.

[13] Oliver C. Ibe, Markov processes for stochastic modeling, 2nd Ed., Elsevier, Inc., Amsterdam, 2013.

[14] Anatoly A. Kilbas, Hari M. SRivastava, Juan J. Trujillo, Theory and applications of fractional differential equations, North-Holland Mathematics Studies, 204, Elsevier Science B. V., Amsterdam, 2006.

[15] V. Lakshmikantham, A. S. Vatsala, Theory of fractional differential inequalities and applications, Commun. Appl. Anal. 11 (2007), no. 3-4, 395-402. 
[16] V. Lakshmikantham, A. S. Vatsala, Basic theory of fractional differential equations, Nonlinear Anal. 69, (2008), no. 8, 2677-2682.

[17] Agnieszka B. Malinowska, Tatiana Odzijewicz and Delfim F. M. Torres, Advanced methods in the fractional calculus of variations, SpringerBriefs in Applied Sciences and Technology, Springer, Cham, 2015.

[18] Keith B. Oldham and Jerome Spanier, The fractional calculus, Academic Press [A subsidiary of Harcourt Brace Jovanovich, Publishers], New York-London, 1974.

[19] Igor Podlubny, Fractional Differential Equations, Mathematics in Science and Engineering, 198, Academic Press, Inc., San Diego, CA, 1999.

[20] Stefan G. Samko, Anatoly A. Kilbas and Oleg I. Marichev, Fractional Integrals and Derivatives: Theory and Applications, Gordon and Breach Publishers, Yverdon, 1993.

[21] Christopher C. Tisdell, Zhenhai LiU and Shev MacNamara, Basic existence and uniqueness results for solutions to systems of nonlinear fractional differential equations, Dyn. Contin. Discrete Impuls. Syst. Ser. A Math. Anal., 24, 3, (2017), 181-193.

[22] Christopher C. Tisdell, Improved mathematical results and simplified pedagogical. Approaches for Gronwall's inequality for fractional calculus, Fract. Differ. Calc., 8, 1 (2018), 33-41.

[23] Christopher C. Tisdell, Basic existence and a priori bound results for solutions to systems of boundary value problems for fractional differential equations, Electron. J. Differential Equations, 84, 9, 2016.

[24] Chen Jin Chang Fu-Xuan and Wei Huang, Anomalous diffusion and fractional advectiondiffusion equation, Acta Physica Sinica, 53, (2005), 1113-1117.

[25] Liancun Zheng And XinXin Zhang, Modeling and analysis of modern fluid problems, Mathematics in Science and Engineering, Elsevier/Academic Press, London, 2017.

[26] Yong ZHOU, Fractional evolution equations and inclusions: analysis and control, Elsevier/Academic Press, London, 2016. 